
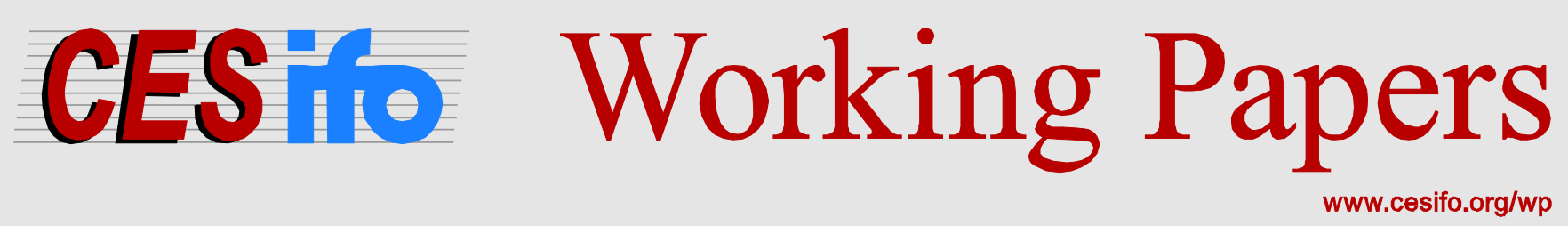

\title{
Optimal Risk-Sharing in Mortgage Contracts: The Effects of Potential Prepayment and Default
}

\author{
Jan K. Brueckner \\ Kangoh Lee
}

\author{
CESIFO WORKING PAPER NO. 4979 \\ CATEGORY 7: MONETARY POLICY AND INTERNATIONAL FINANCE \\ SEPTEMBER 2014
}

An electronic version of the paper may be downloaded

- from the SSRN website:

- from the RePEc website:

- from the CESifo website:

wWW.SSRN.com

Www.RePEc.org

www.CESifo-group.org/wp 


\title{
Optimal Risk-Sharing in Mortgage Contracts: The Effects of Potential Prepayment and Default
}

\begin{abstract}
Much of the literature on the economics of mortgage markets has studied the FRM-ARM choice made by individual borrowers. However, to decide if the outcome of such a choice is efficient or approximately so, it is necessary to explore the question of optimal risk-sharing in mortgage contracts. But since only a small literature has studied this question, more research is clearly warranted. The present paper helps fill this gap by developing a simplified version of Arvan and Brueckner's (1986a) model, using it to characterize optimal contracts in the absence of mortgage termination, and then exploring how termination via prepayment or default affects optimal risk-sharing. The broad conclusion of the analysis is that potential mortgage termination makes higher risk exposure for borrowers optimal.
\end{abstract}

JEL-Code: A000.

Keywords: mortgage, risk-sharing, default, prepayment.

Jan K. Brueckner Department of Economics University of California, Irvine 3151 Social Science Plaza USA - Irvine, CA 92697

jkbrueck@uci.edu
Kangoh Lee Department of Economics San Diego State University 5500 Campanile Drive USA - San Diego, CA 92182

klee@mail.sdsu.edu 


\title{
Optimal Risk-Sharing in Mortgage Contracts: The Effects of Potential Prepayment and Default
}

by

\author{
Jan K. Brueckner and Kangoh Lee*
}

\section{Introduction}

The US mortgage market offers a stunning array of contract choices. The choices range from traditional fixed and adjustable-rate mortgages (FRMs and ARMs) to a variety of hybrid contracts where the rate is fixed for an initial period (as long as ten years) and then adjusts periodically, to nonamortizing mortgages, which include interest-only contracts (usually ARMs) and pay-option ARMs, where the borrower can choose to pay less than the interest due, increasing his indebtedness.

This range of contracts offers a variety of different risk-sharing arrangements. With its fixed rates, the FRM fully protects the borrower from (nominal) interest rate risk, while a traditional ARM offers no risk protection at all, unless it has interest rate caps that restrict the annual rate adjustment. Hybrid contracts offer intermediate degrees of risk protection to the borrower. For lenders, who may secure loanable funds through short-term borrowing at an uncertain rate, risk protection is the mirror image of that enjoyed by the borrower, being entirely absent with an FRM, complete with an ARM, and of intermediate degree with a hybrid contract.

While the literature on mortgage markets is vast, a small piece of it, prompted by the variety of existing contracts, has focused on mortgage risk-sharing and asked the following question: what contract features are necessary for the optimal sharing of interest-rate risk between borrower and lender? This question was first addressed by Arvan and Brueckner (1986a,b), with subsequent contributions by Dokko and Edelstein (1991) and Edelstein and Urošević (2003). Arvan and Brueckner (1986a) showed that, under an optimal contract, interest-rate risk is split between borrower and lender according to the relative sizes of their absolute risk-aversion measures. A future increase in the short-term rate is less fully passed on in a higher loan 
rate, yielding more risk protection for the borrower, the more risk-averse he is relative to the lender. Edelstein and Urošević generalized this finding to account for correlation between the borrower's house value or income level and the short-term rate, with the interest-rate risk protection he enjoys reduced when these correlations are beneficially positive. Dokko and Edelstein follow a different approach to analyzing risk-sharing based on a notion of "risk loading."

The present paper extends this small literature by asking how optimal risk-sharing is affected when two common mortgage-market events, prepayment and default, are taken into account. The analysis uses a simplified version of Arvan and Brueckner's model, and prepayment due to refinancing is considered first. Refinancing can arise in the model because, even though mortgage contracts have a limited two-period term, the economy realistically consists of borrowers of different generations at a given point in time. Borrowers of one generation may then have an incentive to switch from an existing contract to one designed for borrowers of the next generation. In particular, once the second period arrives, borrowers may wish (under some parameter values) to switch to a new mortgage, making a first-period payment under the optimal contract intended for members of the next generation rather than the second-period payment designed for them. As a result, the optimal contract may not be sustainable, and the analysis derives the parameter regions where sustainability obtains or fails. Even though the region of sustainability is appreciable, especially if refinancing involves a transaction cost, the planner could eliminate the refinancing incentive entirely by imposing a sufficiently large prepayment penalty. His other option is to impose an always-sustainable ARM contract, resulting in inefficient risk exposure for borrowers. This conclusion shows that refinancing can have a particularly large effect on risk-sharing by limiting the planner to an extreme type of contract.

The analysis focuses next on prepayment due to job relocation, building on the work of Lee (2014), who identified an inefficient type of mortgage-related "lock-in" that differs from the usual mobility friction due to negative housing equity (see Chan (2001), Engelhardt (2003), and Ferreira, Gyourko and Tracy (2010)). In particular, Lee argued that existing FRM borrowers, who are protected from high interest rates during boom times, may turn down favorable job relocation opportunities that arise in such times in order to avoid forsaking their advantageous 
loan rate (which would happen following a move and reentry into the mortgage market). The resulting inefficiency, Lee argued, can be remedied by increasing the share of borrowers using ARMs, where no lock-in effect exists. The present analysis translates this same intuition into an optimal-contracting framework, showing that potential job relocation reduces the optimal degree of borrower risk protection in boom times. In other words, the optimal mortgage contract more fully exposes the borrower to higher short-term rates when they occur, compared to the case without the chance of job relocation. In good times, this greater risk exposure leads to a loan rate higher than the optimal rate in the absence of potential relocation, reducing the attractiveness of the current mortgage and encouraging the borrower to accept the job offer.

Default has a mirror-image effect on optimal risk-sharing. Default is assumed to be attractive in bust times, when both house prices and short-term interest rates are low. Recognizing that default imposes costs on the lender, the optimal contract attempts to reduce its occurrence by encouraging the borrower to stay in the house. To do so, the optimal loan rate in bust times is reduced relative to the case where default is not possible. This reduction means less borrower risk protection in bust times, with the loan rate more responsive to a drop in the cost of funds. Combining the two cases, the possibilities of default and prepayment due to job location reduce the optimal degree of borrower protection from interest-rate risk over the entire business cycle. As seen below, this conclusion is subject to various qualifications, including limitations on the admissible ranges of parameter values. ${ }^{1}$

While the conclusions just described are developed in sections 3, 4 and 5 of the paper, section 2 sets up the simplified version of the Arvan-Brueckner model used in the analysis. The model has two periods, like theirs, but it assumes that the short-term interest rate follows a random walk, thus taking discrete values (they assumed a continuous distribution of rates). While section 2 replicates the main findings of Arvan and Brueckner (1986a) for use as a benchmark in the ensuing analysis, it also generates additional results that were previously unavailable because of their continuous formulation.

A related theoretical literature has considered the design of mortgage contracts in the presence of asymmetric information and adverse selection, a situation that does not arise in the present full-information context. In the presence of adverse selection, optimal contracts 
rely on screening to partly protect lenders from the higher risks of default or prepayment among particular borrower groups, effectively making such borrowers pay for their greater riskiness. In this sense, these contracts involve a kind of risk-sharing between borrowers and lenders, even though lenders are typically assumed to be risk neutral. In an early contribution to this literature, Stiglitz and Weiss (1981) use a general model of loan contracts to demonstrate that credit rationing is a solution to adverse selection. Other studies demonstrate that points and prepayment penalties serve to screen borrowers who differ in terms of mobility or tendency to terminate contracts early (Dunn and Spatt (1985), Chari and Jagannathan (1989), Brueckner (1994), LeRoy (1996), Stanton and Wallace (1998)), while others show that ARMs also serve as a screening mechanism, as borrowers with a higher probability of moving self-select into ARMs (Brueckner (1992), Rosenthal and Zorn (1993), Posey and Yavas (1999)). Further work argues that the choice of loan-to-value ratio signals a borrower's default risk, with lenders using such signals in designing contracts (Brueckner (2000), Harrison Noordewier and Yavas (2004)).

Piskorski and Tchistyi (2010), building on work by Demarzo and Sannikov (2006) and DeMarzo and Fishman (2007), analyze another type of optimal contracting problem where asymmetric information involves the borrower's income, and where sharing of interest-rate risk is not an issue given lender risk-neutrality. In their continuous-time model, a contract specifies a time profile of payments, which is based on the borrower's reported income stream, along with a termination date for the contract. The optimal contract maximizes the lender's expected payoff subject to a fixed expected utility for the borrower while eliciting truthful reporting of income and generating no incentive for default. The authors argue that the resulting optimal contract resembles an pay-option ARM, allowing payments that fall short of interest on the loan.

This paper's exploration of optimal contracts is also related to existing empirical work on mortgage choice, which has mainly studied the FRM-ARM choice and identified mortgage pricing terms and borrower characteristics as key determinants of the outcome. Dhillon, Shilling and Sirmans (1987), Brueckner and Follain (1988), Nothaft and Wang (1992) show that the choice is strongly affected by the FRM-ARM rate differential, while Brueckner and Follain (1988) and Campbell and Cocco (2003) show that borrower mobility and incomes also matter. 
As ARM rates are uncertain, the choice also depends on interest-rate expectations (Nothaft and Wang (1992), Sa-Aadu and Sirmans (1995), Koijen, Hemert and Nieuwerburgh (2009)).

As explained above, section 2 of the paper introduces the model, while section 3 considers incentives for refinancing. Section 4 analyzes the effect on optimal risk-sharing of prepayment due to job relocation, while section 5 analyzes the effect of default. Section 6 discusses the implications of the analysis for actual mortgage markets, while section 7 offers conclusions.

\section{The Optimal Contract without Termination}

This section analyzes the optimal mortgage contract under the assumption that the mortgage is not terminated. While establishing the structure of the model, the results of this analysis provide a benchmark for the subsequent discussion, which focuses on the effects of potential mortgage termination on the nature of the optimal contract.

Suppose that borrowers live for two periods, and that each generation produces offspring in the second period of life. Since each generation requires a mortgage, new mortgages are originated in every period, with lenders relying on short-term borrowing (either from deposits or the capital market) as the source of funds. Mortgages have a term of two periods and are 100-percent, interest-only loans. The size of the mortgage, which equals the purchase price of the house, is normalized to unity. The loan is paid off with the proceeds from sale of the house at the end of the second period, and the house price is assumed to be constant over time (this assumption is relaxed in section 5's analysis of default).

The utility functions of the borrower and the lender are $u(\cdot)$ and $v(\cdot)$, respectively, with $u^{\prime \prime}, v^{\prime \prime} \leq 0$ holding, and the respective discount factors are $\delta$ and $\theta$. The short-term interest rate in period $\tau$ is denoted $s_{\tau}$, and this rate is assumed to follow a random walk, rising (falling) by $\alpha$ between period $\tau$ and $\tau+1$ with probability $p=1 / 2$. The first-period interest rate on a mortgage originated in period $\tau$ is denoted $r_{\tau, 0}$, while $r_{\tau, 1}^{H}\left(r_{\tau, 1}^{L}\right)$ denote the second-period rates on that mortgage in the event that the short-term rate rises (falls) between periods $\tau$ and $\tau+1$. Conditional on $s_{\tau}$, these two second-period $H$ and $L$ states are referrred to as the "high" and "low" states, and the $r$ 's are referred to as "loan rates." Formally, a mortgage contract is defined as follows: 
Definition. A mortgage contract is rule that generates, in any period $\tau$, an initial loan interest rate $r_{\tau, 0}$ conditional on the initial short-term rate $s_{\tau}$, along with two additional interest rates, $r_{\tau, 1}^{H}$ and $r_{\tau, 1}^{L}$, which specify, respectively, the second-period loan rates in the event that the short-term rate rises or falls between the periods.

The planner chooses the form of the mortgage contract taking into account the expected utilities of both the borrower and lender. His goal is to choose a Pareto-optimal contract, which maximizes the borrower's expected utility subject to a fixed expected-utility level for the lender. For a borrower born in period $\tau$, expected utility is

$$
\epsilon_{\tau} \equiv u\left(y-r_{\tau, 0}\right)+\delta\left[p u\left(y-r_{\tau, 1}^{H}\right)+(1-p) u\left(y-r_{\tau, 1}^{L}\right)\right]
$$

Lender profit equals the loan rate minus the short-term rate, and given the assumed evolution of the short-term rate, the expected utility of profit for a mortgage originated in period $\tau$ is

$$
\pi_{\tau} \equiv v\left(r_{\tau, 0}-s_{\tau}\right)+\theta\left[p v\left(r_{\tau, 1}^{H}-\left(s_{\tau}+\alpha\right)\right)+(1-p) v\left(r_{\tau, 1}^{L}-\left(s_{\tau}-\alpha\right)\right)\right]
$$

The profit constraint is written $\pi_{\tau}-\bar{\pi}=0$, where $\bar{\pi}$ is the fixed expected utility of profit from a mortgage contract. The planner's Lagrangean expression is generated by appending a Lagrange multiplier $\lambda_{\tau}$ to the LHS of this constraint and adding the result to (1).

The first-order conditions for a mortgage originated at $\tau$ are the profit constraint along with

$$
\begin{aligned}
-u^{\prime}\left(y-r_{\tau, 0}\right)+\lambda_{\tau} v^{\prime}\left(r_{\tau, 0}-s_{\tau}\right) & =0 \\
-\delta u^{\prime}\left(y-r_{\tau, 1}^{H}\right)+\lambda_{\tau} \theta v^{\prime}\left(r_{\tau, 1}^{H}-\left(s_{\tau}+\alpha\right)\right) & =0 \\
-\delta u^{\prime}\left(y-r_{\tau, 1}^{L}\right)+\lambda_{\tau} \theta v^{\prime}\left(r_{\tau, 1}^{L}-\left(s_{\tau}-\alpha\right)\right) & =0 .
\end{aligned}
$$

Dividing (4) and (5) by (3) yields

$$
\begin{aligned}
\frac{\delta u^{\prime}\left(y-r_{\tau, 1}^{H}\right)}{u^{\prime}\left(y-r_{\tau, 0}\right)} & =\frac{\theta v^{\prime}\left(r_{\tau, 1}^{H}-\left(s_{\tau}+\alpha\right)\right)}{\left.v^{\prime}\left(r_{\tau, 0}-s_{\tau}\right)\right)} \\
\frac{\delta u^{\prime}\left(y-r_{\tau, 1}^{L}\right)}{u^{\prime}\left(y-r_{\tau, 0}\right)} & =\frac{\theta v^{\prime}\left(r_{\tau, 1}^{L}-\left(s_{\tau}-\alpha\right)\right)}{v^{\prime}\left(r_{\tau, 0}-s_{\tau}\right)} .
\end{aligned}
$$


To derive the implications of (6) and (7), let $\sigma_{u}=-u^{\prime \prime} / u^{\prime}$ and $\sigma_{v}=-v^{\prime \prime} / v^{\prime}$ denote the absolute risk-aversion measures for the borrower and lender, and for simplicity, assume that they are constant. This assumption holds if and only if $u(x)=\rho_{u}-e^{-\sigma_{u} x}$ and $v(x)=\rho_{v}-e^{-\sigma_{v} x}$. Using these utility functions, (6) reduces to

$$
\delta \exp \left[-\sigma_{u}\left(r_{\tau, 1}^{H}-r_{\tau, 0}\right)\right]=\theta \exp \left[-\sigma_{v}\left(r_{\tau, 1}^{H}-r_{\tau, 0}\right)\right]
$$

Taking logs and rearranging, (8) can be rewritten as

$$
\begin{aligned}
r_{\tau, 1}^{H} & =r_{\tau, 0}+\frac{\sigma_{v}}{\sigma_{u}+\sigma_{v}} \alpha+\frac{\ln \theta-\ln \delta}{\sigma_{u}+\sigma_{v}} \\
& =r_{\tau, 0}+\beta \alpha+\gamma
\end{aligned}
$$

where

$$
\beta \equiv \frac{\sigma_{v}}{\sigma_{u}+\sigma_{v}} \leq 1, \quad \gamma \equiv \frac{\ln \theta-\ln \delta}{\sigma_{u}+\sigma_{v}}>(<) \quad 0 \quad \text { as } \quad \theta>(<) \delta .
$$

Similarly, (6) reduces to

$$
r_{\tau, 1}^{L}=r_{\tau, 0}-\beta \alpha+\gamma
$$

Therefore, the second-period loan rates equal the first-period rate plus or minus a term $\beta \alpha$ plus a shift factor $\gamma$, whose sign depends on the relative sizes of the borrower and lender discount factors. If the borrower is impatient relative to the lender (if $\delta \leq \theta$ ), then this shift factor is positive, so that interest payments are pushed into the second period, whereas payment is shifted toward the first period otherwise. The $\beta \alpha$ term shows the extent to which changes in the cost of funds are passed on to borrowers. Referring to (10), this pass-through is greater the smaller is $\sigma_{u}$ relative to $\sigma_{v}$. The pass-through is one-for-one $(\beta=1)$ if $\sigma_{u}=0$, with risk-neutral borrowers bearing all the short-term interest-rate risk. If, on the other hand, $\sigma_{v}=0$, then the pass-through is zero $\left(\beta=0\right.$, so that $\left.r_{\tau, 1}^{H}=r_{\tau, 1}^{L}\right)$, with all the interest-rate risk being born by the risk-neutral lenders. 
The first case resembles a fully adjustable ARM, while the second case resembles an FRM. But in order for these matches to be exact, $\gamma=0$ must hold, with the two discount factors being equal. To see that $\gamma=0$ generates an FRM when $\sigma_{v}=0$, note that these assumptions yield $r_{\tau, 1}^{H}=r_{\tau, 1}^{L}=r_{\tau, 0}$ from (9) and (11), so that a constant loan rate is charged in both periods.

To consider the ARM case, the solution for $r_{\tau, 0}$ is needed. It comes from solving the first-order condition (3), which yields

$$
r_{\tau, 0}=\beta s_{\tau}+k_{\tau}
$$

where

$$
k_{\tau} \equiv \frac{\ln \lambda_{\tau}+\ln \sigma_{v}-\ln \sigma_{u}+\sigma_{u} y}{\sigma_{u}+\sigma_{v}}
$$

Note that, because $\lambda_{\tau}$ is endogenous, $k_{\tau}$ is an unknown constant yet to be determined. To see the exact ARM equivalence when $\sigma_{u}=0$ and $\gamma=0$, note that with $\beta$ then equal to 1 , $r_{\tau, 0}=s_{\tau}+k_{\tau}, r_{\tau, 1}^{H}=s_{\tau}+\alpha+k_{\tau}$, and $r_{\tau, 1}^{L}=s_{\tau}-\alpha+k_{\tau}$, so that the loan rate in each period is given by a common markup $k_{\tau}$ over the cost of funds. Markups would be different in the second period, equal to $k_{\tau}+\gamma$ versus $k_{\tau}$, when $\gamma$ is non-zero. Note that the presence of a first-period teaser rate would correspond to $\gamma>0$. As seen below, the size of the ARM markup will be independent of the origination date of the mortgage.

With $k_{\tau}$ determining $r_{\tau, 0}$ conditional on $s_{\tau}$ from (12), and with (9) and (11) then giving $r_{\tau, 1}^{H}$ and $r_{\tau, 1}^{L}$, the entire solution for the optimal mortgage is given once $k_{\tau}$ is known. The value of $k_{\tau}$ is determined by the lender's profit constraint. Substituting (9), (11), and (12) into the constraint (2), it reduces to

$$
\begin{gathered}
\bar{\pi}=v\left(\beta s_{\tau}+k_{\tau}-s_{\tau}\right)+\theta\left[p v\left(\beta s_{\tau}+k_{\tau}+\beta \alpha+\gamma-\left(s_{\tau}+\alpha\right)\right)\right. \\
\left.+(1-p) v\left(\beta s_{\tau}+k_{\tau}-\beta \alpha+\gamma-\left(s_{\tau}-\alpha\right)\right)\right] \\
=v\left((\beta-1) s_{\tau}+k_{\tau}\right)+\theta\left[p v\left((\beta-1) s_{\tau}+k_{\tau}+(\beta-1) \alpha+\gamma\right)\right. \\
\left.\quad+(1-p) v\left((\beta-1) s_{\tau}+k_{\tau}-(\beta-1) \alpha+\gamma\right)\right]
\end{gathered}
$$


Note that when $\beta<1, k_{\tau}$ and $s_{\tau}$ are positively related, so that a higher of cost of funds $s_{\tau}$ requires a higher markup $k_{\tau}$ above $\beta s_{\tau}$. When $\beta=1$, however, $s_{\tau}$ disappears from (14) and $k_{\tau}$ is independent of the cost of funds and thus independent of $s_{\tau}$ and $\tau$.

While (14) can be viewed as determining $k_{\tau}$ conditional on $s_{\tau}$, the equation also determines a constant value for $(\beta-1) s_{\tau}+k_{\tau}$ given that all the other expressions are independent of $\tau$. Letting this value be denoted $g$, the equality $(\beta-1) s_{\tau}+k_{\tau}=g$ then implies $\beta s_{\tau}+k_{\tau}=s_{\tau}+g$. But since the LHS expression is just $r_{\tau, 0}$, it follows that

$$
r_{\tau, 0}=s_{\tau}+g
$$

so that the initial rate is given by a markup over the cost of funds, which unlike $k_{\tau}$, is independent of $s_{\tau}$. While it was just seen that this relationship held when $\beta=1$, (15) shows that it holds regardless of the form of the mortgage contract.

The markup $g$ depends on the parameter values, and this dependence can be explored by rewriting (14) as

$$
\pi \equiv v(g)+\theta[p v(g+(\beta-1) \alpha+\gamma)+(1-p) v((g-(\beta-1) \alpha+\gamma)]=\bar{\pi} .
$$

This condition determines the markup $g$ as a function of all the parameters in the model. However, since the effects of $\gamma$ and $\beta$ are of principle interest, the function is written as $g=g(\gamma, \beta)$, with $\alpha$ suppressed and $\theta$ viewed as fixed, so that variation in $\gamma$ comes from variation in $\delta$ relative to $\theta$. In addition, noting from (10) that $\gamma$ depends on the sum of $\sigma_{u}$ and $\sigma_{v}$ while $\beta$ (which can be written as $\left.1 /\left(\left(\sigma_{u} / \sigma_{v}\right)+1\right)\right)$ depends on their ratio, independent variation in $\beta$ and $\gamma$ requires fixing $\sigma_{u}+\sigma_{v}$ at some constant value while varying the ratio of $\sigma_{v}$ and $\sigma_{u}$. Therefore, an increase in $\beta$ holding $\gamma$ fixed is achieved by raising $\sigma_{v}$ and reducing $\sigma_{u}$

To evaluate the partial derivatives $g_{\gamma}$ and $g_{\beta}$, let $v^{\prime H}$ and $v^{\prime L}$ denote the derivatives of the second and third $v$ expressions in (16), which are evaluated in the high and low states. Then, the partial derivative $\pi_{\gamma}$ equals $\theta\left(p v^{\prime H}+(1-p) v^{\prime L}\right)>0, \pi_{g}=v^{\prime}(g)+\pi_{\gamma}>0$, and 
$\pi_{\beta}=\alpha \theta\left(p v^{\prime H}-(1-p) v^{\prime L}\right)>0$, where the inequality assumes $\beta<1$ and follows from $v^{\prime \prime}<0$ and $p=1 / 2$. Using these expressions, $g_{\gamma}=-\pi_{\gamma} / \pi_{g}<0$ and $g_{\beta}=-\pi_{\beta} / \pi_{g}<0$. Therefore the markup $g$ over the cost of funds becomes smaller as the borrower becomes less patient relative to the lender (as $\gamma$ increases, with $\delta$ falling) or as the borrower becomes less risk averse relative to the lender (as $\beta$ increases, with $\sigma_{u}$ falling and $\sigma_{v}$ rising).

Summarizing the previous results yields

Proposition 1. In the absence of termination, the optimal mortgage contract has the following features:

(i) The initial loan rate is given by a markup over the initial short-term rate. The markup, which can take either sign, is independent of the short-term rate but dependent on the parameters of the model.

(ii) The second-period loan rate equals the initial rate plus two terms. The first term is a fractional pass-through of the change in the short-term rate, with the fraction depending on the relative magnitudes of absolute risk aversion for the borrower and lender. The second term is a shift factor that is independent of the second-period short-term rate but whose sign depends on relative magnitudes of the discount factors for the borrower and lender.

An additional question concerns the sign of the markup $g$. To investigate this question, assume that $\bar{\pi}$ corresponds to the zero profit level that would be earned in competitive shortterm lending, so that $\bar{\pi}=(1+\theta) v(0)$. Given this value of $\bar{\pi}, g>0$ must hold when $\gamma=0$, assuming $\beta<1$. To see why, observe first that $\pi<v(g)+\theta v(g+\gamma)$ holds given $v^{\prime \prime}<0$, $p=1 / 2$, and $\beta<1$. As a result, if $g=\gamma=0$, then $\pi<\bar{\pi}$. Since $\pi_{g}>0$, it then follows that $\pi=\bar{\pi}$ requires $g>0$ when $\gamma=0$, as claimed. But with $g>0$ when $\gamma=0$ and with $g_{\gamma}<0$, it follows that there exists a critical $\gamma$ value $\gamma^{*}>0$ such that $g>(<) 0$ as $\gamma<(>) \gamma^{*}$. Therefore, the markup $g$ is positive for low values of $\gamma$ and negative for high values. Instead of being positive, $\gamma^{*}=0$ if $\beta=1 .^{2}$

Note that, since $\gamma^{*}$ is implicitly defined by $g\left(\gamma^{*}, \beta\right)=0$, it is function of $\beta$, written $\gamma^{*}(\beta)$. Since $g_{\gamma}<0$ and $g_{\beta}<0$ when $\beta<1$, this function is decreasing. The above inequality can then be rewritten as $\gamma<(>) \gamma^{*}(\beta)$, and in this form, the two directions of the inequality require $(\gamma, \beta)$ to lie in two different regions of the parameter space. Conditional on $\beta$, however, the inequality is just a statement about required values of $\gamma$. 
Similar analysis, presented in the appendix, can be used to derive additional results relating the sign of lender profits in the high and low states to the magnitude of $\gamma$, conditional on $\beta$. These results will be useful in the analysis of sections 4 and 5. Referring to (16), these two profit expressions are $g(\gamma, \beta)+(\beta-1) \alpha+\gamma$ and $g(\gamma, \beta)-(\beta-1) \alpha+\gamma$, respectively. The relevant results, along with the previous conclusion regarding $\gamma^{*}$, are summarized as follows:

Proposition 2. Three critical values of $\gamma$ exist, whose properties are as follows when $\beta<1$ :

(i) There exists a critical value $\gamma^{*}(\beta)>0$ such that the markup $g$ of the initial rate over the initial short-term rate is positive (negative) as $\gamma<(>) \gamma^{*}(\beta) . \gamma^{*}$ is decreasing in $\beta$.

(ii) There exists a second critical value $\gamma^{L}(\beta)<0<\gamma^{*}(\beta)$ such that the lender's profit in the low state is negative (positive) as $\gamma<(>) \gamma^{L}(\beta) . \gamma^{L}$ is increasing in $\beta$.

(iii) There exists a third critical value $\gamma^{H}(\beta)>\gamma^{*}(\beta)$ such that the lender's profit in the high state is negative (positive) as $\gamma<(>) \gamma^{H}(\beta) . \gamma^{H}$ is decreasing in $\beta$.

When $\beta=1, \gamma^{*}(\beta)=\gamma^{L}(\beta)=\gamma^{H}(\beta)=0$.

Note that the inequalities in (ii) and (iii) are statements involving the value of $\gamma$ conditional on $\beta$. Viewed unconditionally, they are statements about the location of the $(\gamma, \beta)$ vector in the overall parameter space.

\section{The Effect of Potential Refinancing}

\subsection{Main analysis}

The optimal mortgage characterized so far may not be sustainable in a market context because, assuming it is feasible, borrowers may wish to refinance in period $\tau+1$, switching to a new mortgage designed for borrowers born in this period. In this case, the borrower relies on this mortgage for only one period, paying it off at the end of his life. Refinancing will be attractive in the low state when

$$
r_{\tau+1,0}<r_{\tau, 1}^{L},
$$

or when the first-period loan rate on a new mortgage is less than the second-period rate on the 
existing mortgage, assuming that the low state prevails. The initial rate on a new mortgage is $r_{\tau+1,0}=s_{\tau+1}+g$ from (15), and substituting from (11) and (15) to get $r_{\tau, 1}^{L}$, (17) becomes

$$
s_{\tau+1}+g<s_{\tau}+g-\beta \alpha+\gamma
$$

Since since $s_{\tau+1}=s_{\tau}-\alpha$ holds in the low state, (17) reduces to

$$
-(1-\beta) \alpha<\gamma . \quad(\text { low state })
$$

The condition for refinancing in the high state, $r_{\tau+1,0} \leq r_{\tau, 1}^{H}$, is gotten by adding rather than subtracting $\beta \alpha$ in (18) and using $s_{\tau+1}=s_{\tau}+\alpha$. Therefore, the refinancing condition reduces to

$$
(1-\beta) \alpha<\gamma . \quad \text { (high state) }
$$

Assuming $\beta<1$, the implications of (19) and (20) are as follows:

$$
\begin{aligned}
& -(1-\beta) \alpha<(1-\beta) \alpha<\gamma \Rightarrow \text { refinance in both } L \text { and } H \\
& -(1-\beta) \alpha<\gamma \leq(1-\beta) \alpha \Longrightarrow \text { refinance in } L \text { not in } H \\
& \gamma \leq-(1-\beta) \alpha<(1-\beta) \alpha \Longrightarrow \text { refinance in neither } L \text { nor } H
\end{aligned}
$$

These conclusions show that, if the borrower refinances in the high state, he also refinances in the low state. When $\beta=1$, the middle case in (22) disappears, and the borrower refinances in both states if $\gamma>0$ and refinances in neither state if $\gamma \leq 0$. Then, the following conclusion can be stated:

Proposition 3. The optimal mortgage contract is unsustainable, with borrowers having an incentive to refinance in one or both states, when $\gamma>-(1-\beta) \alpha$ holds. Unsustainability is more likely when the borrower is impatient relative to the lender (when $\gamma$ is large), when the borrower's absolute risk aversion is high relative to that of the lender (when $\beta$ is small), and when volatility of the short-term interest rate is high ( $\alpha$ is large). 
To understand these conclusions, note that when the borrower is impatient, interest payments are shifted toward the second period, allowing high consumption in the initial period. This shift raises the second-period loan rate in both the high and low states, making it less attractive relative to the initial rate on a new mortgage and thus increasing the incentive to refinance. Substantial risk-sharing, reflected in a low value of $\beta$, limits the pass-through of the lower cost of funds in the low state, keeping the second-period loan rate relatively high and increasing the incentive to switch to a new mortgage. With a larger value of $\alpha$, the absolute size of the initial rate's decline in the low state grows relative to the decline in the second-period rate on the existing mortgage, making it more likely that the latter rate is unattractive. ${ }^{3}$

These arguments are illustrated in Figure 1, which assumes $\beta<1$. The horizontal axis shows different values of $\gamma$, positive and negative, while the vertical axis shows, for the high and low states, the initial rate on a new mortgage (marked by the upper and lower solid horizontal lines) and the second-period rate on the existing mortgage when $\gamma=0$ (marked by the intermediate dashed horizontal lines). The second-period rates are also plotted for different nonzero values of $\gamma$ along four different dashed vertical lines.

The vertical axis shows that, when $\gamma=0$, refinancing is desirable in the low state (the lower solid horizontal line is below the lower dashed horizontal line) but not in the high state (the upper solid line is above the upper dashed line). The two inner vertical dashed lines correspond to two cases where $\gamma \in[-(1-\beta) \alpha,(1-\beta) \alpha]$, leaving the previous conclusions unchanged. In particular, the second-period loan rates in the two states move up on the inner right line and down on the inner left line, but they remain between the horizontal solid lines. When $\gamma$ is larger than $(1-\beta) \alpha$ (corresponding to the rightmost vertical line), the second-period rate in the high state moves above the upper solid horizontal line, so that refinancing is desirable in both the high and low states. When $\gamma$ is less than $-(1-\beta) \alpha$ (corresponding to the leftmost vertical line), the second-period rate in the low state moves below the lower solid horizontal line, so that refinancing is undesirable in both the high and low states.

While Figure 1 shows the effect of different $\gamma^{\prime}$ s, the effects of $\beta$ and $\alpha$ can be seen as well. For example, focusing on the inner right vertical line, an increase in $\beta$ can raise the upper point above the upper solid horizontal line, making refinancing desirable rather than 
undesirable in the high state (the lower point remains above the lower dashed line). Focusing on the leftmost vertical line, if $\alpha$ increases, then the lower point and the lower solid horizontal line shift down, but the solid line shifts down by more, an outcome that can put the point above rather than below the line. As a result, the increase in $\alpha$ can make refinancing desirable rather than undesirable in the low state.

In reality, refinancing involves a transaction cost, which has been ignored so far, and if this cost is added to model, the incentive to refinance is reduced. Letting the cost be denoted $c$, its presence means that $c$ must be added to the LHS of (17), so that the inequality becomes $c-(1-\beta) \alpha<\gamma$, with $c$ also added to the LHS of (20). Unsustainability of the mortgage contract now requires $\gamma>c-(1-\beta) \alpha$, a more-stringent condition that is harder to satisfy for large values of $c .^{4}$

\subsection{Remedies for unsustainability?}

With possible unsustainability of the optimal mortgage contract, it is natural to think that the requirement of sustainability should be incorporated into the contract design. Such an approach, however, is not possible using the current framework. To see why, observe that sustainability would require imposing a "no-refinancing" constraint that links the secondperiod rate on a given mortgage to the initial rate on separate, yet-to-be-written, mortgage contract. Such a constraint is logically impossible under the current approach, which focuses on the design of self-contained mortgage contracts. Despite this prohibition, it is still possible to analyze the effect of refinancing on a particular contract feature, namely, the markup $g$, conditional on a given contractual form. For example, in the case of an FRM contract (generated by $\beta=\gamma=0$ ), refinancing will always occur in the profitable low state, requiring a higher markup to satisfy the lender's profit constraint. Similarly, refinancing that occurs under other $\beta$ and $\gamma$ values will require appropriate adjustment of the markup. The point to recognize, however, is that the possibility of refinancing cannot be taken into account in the design of the contract under the current approach. ${ }^{5}$

By contrast, the effect on contract design of other types of mortgage termination can be analyzed, as will be seen in the next two sections. In these cases, the borrower either foresakes the mortgage market upon termination (as happens with default) or switches to a mortgage 
contract intended for a higher-income borrower type (as happens with job relocation). This post-termination separability allows the design of the original contract to be adjusted to reduce the likelihood of termination, something that is impossible when termination puts the borrower into a contract with the same form as the one he is terminating.

Despite the impossibility of designing a sustainable mortgage under the current approach, one particular type of contract is immune to refinancing for all parameter values and regardless of which state occurs. This contract is the fully adjustable ARM, where the loan rate in any period is given by a fixed markup over the cost of funds. Under this ARM contract, the secondperiod loan rate equals the rate on a new mortgage in both the high and low states, eliminating the incentive to refinance. While the planner could meet the requirement of sustainability by imposing a fully adjustable ARM, a contract of this form is optimal only when $\beta=1$ and $\gamma=0$, with an efficiency loss, potentially a large one, emerging under other parameter values. This loss shows that the threat of refinancing can have a very large effect on the scope of possible risk-sharing, limiting the planner to an extreme type of contract.

However, the resulting efficiency loss could be avoided, with the sustainability question circumvented, if the planner were able to impose a prepayment penalty and to choose one of sufficient size. Such a penalty would eliminate the incentive to refinance and allow mortgage contracts embodying optimal risk-sharing to be implemented (Mayer, Piskorski and Tchistyi (2013) make a similar point in a very different model).

\section{The Effect of Termination Due to Job Relocation}

While much attention has been paid to the lock-in effect of negative housing equity, risksharing in mortgage contracts can also generate lock-in. By sheltering the borrower from a increase in the lender's cost of funds, an increase that is likely to occur during boom times when new jobs are plentiful, risk-sharing may inhibit efficient labor-market mobility. To see how, note that to take a new higher-paying job in another city, the borrower would have to prepay his mortgage, sacrificing a relatively low risk-protected interest rate for a potentially higher initial rate on a new mortgage, a rate that reflects the current high cost of funds. This sacrifice, along with the burden of moving costs, may cause the borrower to pass up the job 
opportunity, an inefficient outcome from a labor-market perspective. This outcome suggests that labor-market considerations may reduce the optimal extent of risk-sharing in the mortgage market, with a higher loan rate called for in the high state in order to encourage job relocation.

The model can be used to illustrate this effect in a stylized fashion through adoption of some additional assumptions, while assuming $\beta<1$, so that the original contract from section 2 involves risk-sharing. First, suppose that the transaction $\operatorname{cost} c$ is large enough to eliminate prepayments motivated purely by interest-rate changes. Second, for borrowers starting out with income $y$, the offer of a job paying $\widetilde{y}>y$ arrives with probability $q$ in the high state, where the high short-term rate reflects better business conditions (no offer is received in the low state). While the income from this job is thus earned in the second period of life, some borrowers hold higher paying jobs throughout their lives. Third, taking the higher-paying job requires residential relocation and thus prepayment of the mortgage and origination of a new one. Because of the income gain, payment of the resulting transaction cost may be worthwhile. Fourth, mortgages can be tailored according to the income of the borrower. Borrowers whose income is initially low at $y$, who have chance of earning a higher income through job relocation, get a different mortgage than borrowers born into the higher-income job (who are assumed have no further prospects of advancement). Fifth, the moving cost, which is denoted $m$, is a random variable whose realization is known only at the time a job offer is received. It has support $[0, \bar{m}]$ and cumulative distribution function $F(\cdot)$. This randomness is plausible given that moving cost is broadly interpreted to include economic and non-economic psychological costs. For instance, the job's benefits may depend on its exact location, which determines distance from current friends and relatives. In addition, the job may be more or less pleasant than the current one, an effect that can be captured in $m$. These stylized assumptions are crafted to allow a tractable analysis.

Let the loan rates for a contract designed for high-income borrowers, who have income $\widetilde{y}$ in both periods, be denoted with a tilde. These interest rates are the ones derived in section 2, which do not depend on income but do reflect the absence of termination. Assuming for simplicity that the moving cost $m$ is measured in utility terms, the gain from moving to a 
higher income job is

$$
u\left(\widetilde{y}-\widetilde{r}_{\tau+1,0}-c\right)-m-u\left(y-r_{\tau, 1}^{H}\right) .
$$

The gain reflects the utility from the higher income less the initial payment on a new mortgage $\left(\widetilde{r}_{\tau+1,0}\right)$ less transaction costs. Moving cost and the forgone second-period utility from the original mortgage are then subtracted. The job offer is accepted when (24) is positive or zero, requiring that $m \leq \widetilde{m} \equiv \widetilde{u}-u\left(y-r_{\tau, 1}^{H}\right)$ holds, where $\widetilde{u} \equiv u\left(\widetilde{y}-\widetilde{r}_{\tau+1,0}-c\right)$. Then the probability of that the borrower moves is

$$
z=F(\widetilde{m})
$$

which is increasing with $r_{\tau, 1}^{H}$ given

$$
\frac{\partial z}{\partial r_{\tau, 1}^{H}}=f(\widetilde{m}) \frac{\partial \widetilde{m}}{\partial r_{\tau, 1}^{H}}=f(\widetilde{m}) u^{\prime}\left(y-r_{\tau, 1}^{H}\right)>0
$$

The expected utility of a borrower born into the low-income job in period $\tau$ is

$$
\begin{aligned}
u\left(y-r_{\tau, 0}\right) & +\delta\left(p q \int_{0}^{\tilde{m}}(\widetilde{u}-m) f(m) d m+p[q(1-z)+1-q] u\left(y-r_{\tau, 1}^{H}\right)\right. \\
& \left.+(1-p) u\left(y-r_{\tau, 1}^{L}\right)\right) .
\end{aligned}
$$

Note that the first term after the $\delta$ equals the probability of the high state $(p)$ times the probability of a high-income offer in that state $(q)$ times the expectation of the post-move utility $\widetilde{u}-m$ when the job is accepted. The probability of keeping the same income and mortgage payment is the probability that an offer is received in the high state but not accepted $(p q(1-z))$ plus the probability that an offer is not received $(p(1-q))$.

The lender's expected utility from the mortgage originated for the low-income borrower is

$$
v\left(r_{\tau, 0}-s_{\tau}\right)+\theta\left\{p q z v(0)+p[q(1-z)+1-q] v\left(r_{\tau, 1}^{H}-\left(s_{\tau}+\alpha\right)\right)+(1-p) v\left(r_{\tau, 1}^{L}-\left(s_{\tau}-\alpha\right)\right\} .\right.
$$

Note that the lender earns no income (receiving utility $v(0)$ ) if the borrower moves to the high-income job, thus prepaying the mortgage. 
Subtracting $\bar{\pi}$ from (28) and appending the multiplier $\lambda_{\tau}$, the first-order conditions for choice of $r_{\tau, 0}$ and $r_{\tau, 1}^{L}$ are (3) and (5), which yield (11) and (12) as before. The first-order condition for $r_{\tau, 1}^{H}$ is

$$
\begin{gathered}
p[q(1-z)+1-q]\left[-\delta u^{\prime}\left(y-r_{\tau, 1}^{H}\right)+\lambda_{\tau} \theta v^{\prime}\left(r_{\tau, 1}^{H}-\left(s_{\tau}+\alpha\right)\right)\right]+ \\
p q \lambda_{\tau} \theta\left[v(0)-v\left(r_{\tau, 1}^{H}-\left(s_{\tau}+\alpha\right)\right)\right] \frac{\partial z}{\partial r_{\tau, 1}^{H}}=0 .
\end{gathered}
$$

Note that, in differentiating (27), the terms involving $\widetilde{m}$ and $z$ vanish since the relevant derivative is $\delta p q\left[\widetilde{u}-\widetilde{m}-u\left(y-r_{\tau, 1}^{H}\right)\right] f(\widetilde{m})\left(\partial \widetilde{m} / \partial r_{\tau, 1}^{H}\right)=0$, using the definition of $\widetilde{m}$.

Dividing (29) by (3) and rearranging, the condition reduces to

$$
\frac{\delta u^{\prime}\left(y-r_{\tau, 1}^{H}\right)}{u^{\prime}\left(y-r_{\tau, 0}\right)}-\frac{\theta v^{\prime}\left(r_{\tau, 1}^{H}-\left(s_{\tau}+\alpha\right)\right)}{\left.v^{\prime}\left(r_{\tau, 0}-s_{\tau}\right)\right)}-\frac{q \theta\left[v(0)-v\left(r_{\tau, 1}^{H}-\left(s_{\tau}+\alpha\right)\right)\right]}{\left.[q(1-z)+1-q] v^{\prime}\left(r_{\tau, 0}-s_{\tau}\right)\right)} \frac{\partial z}{\partial r_{\tau, 1}^{H}}=0
$$

The implications of (30) will be derived using Proposition 2, which takes the value of $\beta$ as given and makes statements about lender profit that depend on the value of $\gamma$. However, this approach is broadened below to generate unconditional statements involving the entire vector $(\gamma, \beta)$ and its location in the parameter region.

To derive the implications of (30), let the expression be evaluated at the optimal $r_{\tau, 1}^{H}$ value from the model without termination, assuming $\gamma<\gamma^{H}(\beta)$. From Proposition 2, an optimal value with $\gamma$ in this range generates a loss for the lender in the high state, so that $v(0)-v\left(r_{\tau, 1}^{H}-\left(s_{\tau}+\alpha\right)\right)>0$ holds. Also, at this optimal value, the difference between the first and second terms in (30) equals zero given (6). Since $\partial z / \partial r_{\tau, 1}^{H}>0$, it then follows that the LHS of (30) is negative. The no-termination $r_{\tau, 1}^{H}$ value is thus not optimal with potential job relocation, and it can be seen from (30) that a smaller value cannot be optimal either. In particular, holding $r_{\tau, 0}$ fixed, let $r_{\tau, 1}^{H}$ decrease starting from the no-termination value. Then, the first term in (30) decreases and the second increases, making the difference between them negative, while the third (subtracted) term remains positive. As a result, (30) remains negative. The upshot is that, when $\gamma<\gamma^{H}(\beta)$, the optimal $r_{\tau, 1}^{H}$ with potential job relocation must be 
larger, not smaller, than the no-termination value, so that

$$
r_{\tau, 1}^{H}>r_{\tau, 0}+\beta \alpha+\gamma
$$

The optimal contract thus involves less risk protection for the borrower than in the notermination case, with borrowers more fully exposed to the higher cost of funds in the high state, when $\gamma<\gamma^{H}(\beta)$. With $z$ increasing in $r_{\tau, 1}^{H}$ from (26), it follows that this lower risk protection makes job relocation more likely than under the no-termination contract (for a given $\left.r_{\tau, 0}\right)$.

When $\gamma>\gamma^{H}(\beta)$, so that $v(0)-v\left(r_{\tau, 1}^{H}-\left(s_{\tau}+\alpha\right)\right)<0$ holds, it is easy to see that a parallel argument establishes the reverse of the inequality in (31). The implications of this discussion are therefore as follows:

Proposition 4. With potential job relocation, the optimal mortgage contract involves less (more) high-state risk protection for the borrower than in its absence, with $r_{\tau, 1}^{H}$ higher (lower), conditional on $r_{\tau, 0}$, than in the no-termination case, as $\gamma<(>) \gamma^{H}(\beta)$. This change in risk protection raises (lowers) the probability of job relocation, conditional on $r_{\tau, 0}$.

This result can be understood by noting that job relocation creates an externality felt by the lender. If the lender loses money in the high state, the job mover generates a positive externality by prepaying the money-losing mortgage in this state. On the other hand, when the lender earns a profit in the high state, the externality is negative since job relocation curtails these earnings. To make the appropriate correction, the planner encourages job relocation when the externality is negative by exposing the borrower to more interest-rate risk through a higher $r_{\tau, 1}^{H}$, which increases the attractiveness of moving. When the externality is positive, relocation is discouraged through a lower $r_{\tau, 1}^{H}$ and more rather than less risk protection.

To judge which case is most realistic, recall from Proposition 2 that the initial loan rate embodies a positive markup $g$ over the cost of funds in the absence of termination when $\gamma<\gamma^{*}(\beta)<\gamma^{H}(\beta)$, in which case the externality is positive. Since a positive $g$ prevails in practice, it seems realistic to suppose that a planning solution would also exhibit such a 
markup. Therefore, the positive-externality case would seem to be most relevant, leading to the conclusion that, with termination due to job relocation, borrowers should be exposed to more interest-rate risk than in its absence, raising the probability of job relocation.

While the initial discussion in this section pointed to risk-sharing in mortgages as a source of labor-market inefficiency, this effect is absent in the preceding analysis, which focuses only on the gains to the lender from job relocation. However, this labor-market dimension can be added in a simple fashion by presuming that restraints on relocation will reduce the quality of job matching, as local workers (who can keep existing mortgages) fill job openings in the place of better qualified candidates who would need to relocate. This lower match quality in turn reduces the employer's surplus from the production process, an additional externality that reinforces the one felt by the lender. This externality can be added to the previous analysis in a straightforward fashion, and its presence would strengthen the conclusion that efficiency requires a reduction in borrower risk protection in the high state.

It is important to note that the previous conclusions relate to the form of the rules by which second-period interest rates are determined, without pinning down the actual interestrate levels in that period. In other words, while the rule for determination of the secondperiod rate in the low state conditional on $r_{\tau, 0}$ is unchanged, being given by (11), the rule for determining the rate in the high state is different, yielding a higher value than the old rule, as seen in (31). But the levels of the rates depend on $r_{\tau, 0}$, which will generally be different than in the no-termination case. To find this level, (14) is again used, but the argument of the last $v$ term is replaced by the $r_{\tau, 1}^{H}$ solution from (31), which depends on $s_{\tau}$ and $r_{\tau, 0}=\beta s_{\tau}+k_{\tau}$.

The condition then determines $k_{\tau}$ and thus $r_{\tau, 0}, r_{\tau, 1}^{L}$ and $r_{\tau, 1}^{H}$. The added complexity, however, precludes a comparison of the levels of the rates to those in the no-termination case. As a result, Proposition 4 should be understood as a statement that is conditional on $r_{\tau, 0}$.

\section{The Effect of Termination Due to Default}

\subsection{Main analysis}

The possibility of mortgage default can have a similar effect on optimal risk-sharing. Suppose that the price of the house can fall below its initial value of unity in the low (bust) state, 
doing so with probability $x$. Let the resulting price be denoted $T^{L}<1$. To simplify the discussion, the house price is assumed not to change in the high state. If, in response to this low-state price decline, the borrower defaults on the mortgage, he must move to rental housing, paying a fixed rent of $R^{L}$ in the second period.

If the borrower does not default, he must use additional funds to pay off the mortgage at the end of the second period given that the proceeds from the house are insufficient to do so. This additional payment equals the drop in the house price, or $1-T^{L}$, so that the borrower's utility is $u\left(y-r_{\tau, 1}^{L}-\left(1-T^{L}\right)\right)$. In the case of default, the borrower does not make the second-period interest payment, paying rent instead, and since the mortgage is not repaid, no contribution of additional funds is needed. However, the borrower incurs the moving cost $m$. Therefore utility in the event of default equals $u\left(y-R^{L}\right)-m$. Default costs, which would capture the loss due credit impairment following default (as well as any guilt), can be ignored and are thus set to zero.

Default occurs when the second utility expression is larger that the first, or when $m \leq$ $u\left(y-R^{L}\right)-u\left(y-r_{\tau, 1}^{L}-\left(1-T^{L}\right)\right)=\widetilde{m}$, where $\widetilde{m}$ again denotes the critical moving cost. ${ }^{6}$ Again using $z$ to denote the probability of terminating the mortage,

$$
z=F\left[\widetilde{u}-u\left(y-r_{\tau, 1}^{L}-\left(1-T^{L}\right)\right)\right]=F(\widetilde{m})
$$

where $\widetilde{u}$ now represents $u\left(y-R^{L}\right)$. A higher $r_{\tau, 1}^{L}$ increases $z$, mirroring the similar effect in the job-moving model:

$$
\frac{\partial z}{\partial r_{\tau, 1}^{L}}=f(\widetilde{m}) u^{\prime}\left(y-r_{\tau, 1}^{L}-\left(1-T^{L}\right)\right)>0
$$

The expected utility of the borrower is thus given by an expression similar to (27):

$$
\begin{gathered}
u\left(y-r_{\tau, 0}\right)+\delta\left(p u\left(y-r_{\tau, 1}^{H}\right)+\right. \\
\left.(1-p) x \int_{0}^{\widetilde{m}}(\widetilde{u}-m) f(m) d m+(1-p)[x(1-z)+1-x] u\left(y-r_{\tau, 1}^{L}-\left(1-T^{L}\right)\right)\right) .
\end{gathered}
$$


In the event of default, the lender pays off his depositors with the proceeds from sale of the borrower's house, seized via foreclosure, combined with additional funds that he must contribute. This contribution, which equals $1-T^{L}$, generates a loss for the lender. As a result, the lender's expected utility, which parallels (28), equals

$$
\begin{gathered}
v\left(r_{\tau, 0}-s_{\tau}\right)+\theta\left\{p v\left(r_{\tau, 1}^{H}-\left(s_{\tau}+\alpha\right)\right)+\right. \\
\left.+(1-p) x z v\left(-\left(1-T^{L}\right)\right)+(1-p)[x(1-z)+(1-x)] v\left(r_{\tau, 1}^{L}-\left(s_{\tau}-\alpha\right)\right)\right\} .
\end{gathered}
$$

Deriving the first-order conditions and rearranging as before, the condition for choice of $r_{\tau, 1}^{L}$ can be written as

$$
\begin{aligned}
\frac{\delta u^{\prime}\left(y-r_{\tau, 1}^{L}-\left(1-T^{L}\right)\right)}{u^{\prime}\left(y-r_{\tau, 0}\right)} & -\frac{\theta v^{\prime}\left(r_{\tau, 1}^{L}-\left(s_{\tau}-\alpha\right)\right)}{\left.v^{\prime}\left(r_{\tau, 0}-s_{\tau}\right)\right)} \\
& -\frac{x \theta\left[v\left(-\left(1-T^{L}\right)\right)-v\left(r_{\tau, 1}^{L}-\left(s_{\tau}-\alpha\right)\right)\right]}{\left.[x(1-z)+1-x] v^{\prime}\left(r_{\tau, 0}-s_{\tau}\right)\right)} \frac{\partial z}{\partial r_{\tau, 1}^{L}}=0 .
\end{aligned}
$$

As before, Proposition 2 is used to derive the implications of (36) conditional on the value of $\beta$, with a more comprehensive statement given below. From Proposition 2, $v\left(r_{\tau, 1}^{L}-\left(s_{\tau}-\alpha\right)\right)>$ $v(0)>v\left(-\left(1-T^{L}\right)\right)$ holds at the optimal $r_{\tau, 1}^{L}$ value from the model without termination when $\gamma>\gamma^{L}(\beta)$, so that the last term in (36) is negative at that value. Because of the presence of the $-\left(1-T^{L}\right)$ term, the difference between the first two terms is positive at the no-termination $r_{\tau, 1}^{L}$ value rather than zero. As a result, the LHS of (36) is positive at this value, from which it follows (using the previous argument) that the optimal $r_{\tau, 1}^{L}$ with potential default must be smaller than the optimal no-termination value, so that

$$
r_{\tau, 1}^{L}<r_{\tau, 0}-\beta \alpha+\gamma .
$$

Thus, when $\gamma>\gamma^{L}(\beta)$, the optimal contract exhibits less risk protection for the borrower than the no-termination contract, with borrowers more fully exposed to the drop in the cost 
of funds in the low state. With $z$ increasing in $r_{\tau, 1}^{L}$ from (33), it follows that this lower risk protection reduces the probability of default, for a given $r_{\tau, 0}$.

However, the profit reference point in $(36)$ is $v\left(-\left(1-T^{L}\right)\right)$, not $v(0)$ as before. To make the appropriate adjustment, note that $v\left(r_{\tau, 1}^{L}-\left(s_{\tau}+\alpha\right)\right)<(>) v\left(-\left(1-T^{L}\right)\right)$ will hold as $\gamma<(>) \widehat{\gamma}^{L}(\beta)$, where $\widehat{\gamma}^{L}(\beta)$ is a new critical value less than $\gamma^{L}(\beta)$. Therefore, the last term in (36) is negative at the no-termination $r_{\tau, 1}^{L}$ value, yielding $(37)$, when $\gamma>\widehat{\gamma}^{L}(\beta)$. Note, however, that the sign of the LHS of (36) is ambiguous at the no-termination $r_{\tau, 1}^{L}$ value when $\gamma<\widehat{\gamma}^{L}(\beta)$. While the difference in the first terms is positive, the sign of the last term switches to positive, so that the entire expression becomes ambiguous in sign. The comparison of $r_{\tau, 1}^{L}$ values between the two cases is thus infeasible when $\gamma<\widehat{\gamma}^{L}(\beta)$, so that the two-way statement in Proposition 4 is replaced by the following one-way statement:

Proposition 5. With potential default, the optimal mortgage contract involves less low-state risk protection for the borrower than in its absence, with $r_{\tau, 1}^{L}$ lower, conditional on $r_{\tau, 0}$, than in the no-termination case, when $\gamma>\widehat{\gamma}^{L}(\beta)$. This reduction in risk protection reduces the probability of default, conditional on $r_{\tau, 0}$.

The positive externality felt by the lender in the job-relocation case is now replaced by a negative externality, with the profit earned in the low state replaced by a loss when default occurs, provided $\gamma>\widehat{\gamma}^{L}(\beta)$. By itself, this externality would call for a reduction in $r_{\tau, 1}^{L}$ to increase the borrower's incentive to stay in the house. But the planner has an additional reason to keep $r_{\tau, 1}^{L}$ low. In particular, because disposable income is reduced by the loss from paying off the loan when the borrower stays in the house, the marginal benefit from a reduction in $r_{\tau, 1}^{L}$ is larger (given $u^{\prime \prime}<0$ ) than if the loss were not present. This extra effect reinforces the externality, leading to a lower $r_{\tau, 1}^{L}$ value than in the no-termination case. But when $\gamma<\widehat{\gamma}^{L}(\beta)$ holds, making low-state profit negative, reversing the sign of the externality, and providing an incentive to raise rather than lower $r_{\tau, 1}^{L}$, the continued presence of this borrower-side effect makes the required change in $r_{\tau, 1}^{L}$ ambiguous in sign.

Propositions 4 and 5 show that the optimal contract has less borrower risk protection with potential job relocation (potential default) when $\gamma$ is low (high). If both types of mortgage termination are simultaneously possible (job relocation in the high state and default in the 
low state), the resulting contract would exhibit less risk sharing overall (in both the high and low states) if $\gamma$ satisfies $\widehat{\gamma}^{L}(\beta)<\gamma<\gamma^{H}(\beta)$. If $\gamma$ were realistically constrained to produce a positive markup in the no-termination case, then the range of $\gamma$ values yielding less overall borrower risk protection narrows to $\left[\widehat{\gamma}^{L}(\beta), \gamma^{*}(\beta)\right]$. However, since both ranges cover $\gamma=0$, at which point $\delta=\theta$, the following statement can be made:

Corollary. If the discount factors of the borrower and lender are "close" in magnitude, and if job relocation (default) is possible in the high (low) state, then the optimal mortgage contract exposes the borrower to more overall interest-rate risk than in the no-termination case, conditional on $r_{\tau, 0}$.

Finally, observe that the rules-versus-levels caveat from section 4 also applies in the default case. In other words, since the value of $r_{\tau, 0}$ will differ between the default and no-termination cases, a comparison of the actual levels of the second-period loan rates between the cases is not straightforward. However, a comparison of the risk-sharing rules (which condition on $r_{\tau, 0}$ ) is feasible, as seen above.

\subsection{Removing conditionality on $\beta$}

As explained several times, the results in Propositions 4 and 5 are implicitly conditioned on the value of $\beta$. However, it is straightforward to convert these findings into a statement about required locations of the vector $(\gamma, \beta)$ in the overall parameter space, relying on Proposition 2. Recall from the proposition that $\gamma^{H}(\beta)$ is decreasing in $\beta$ and $\gamma^{L}(\beta)$ is increasing in $\beta$, with both critical values equal to zero when $\beta=1$. Using this information, Figure 2 shows graphs of the critical values as functions of $\beta$, with $\gamma$ on the vertical axis (the curves are shown as straight lines for simplicity). The figure also shows the graph of $\widehat{\gamma}^{L}$, which lies below the $\gamma^{L}(\beta)$ curve.

Recall that for potential job relocation and default to lead to more overall risk exposure for the borrower relative to the no-termination case, $\gamma$ must lie between $\gamma^{H}(\beta)$ and $\widehat{\gamma}^{L}(\beta)$. The $(\gamma, \beta)$ parameter values leading to this outcome thus lie in the shaded region in the figure, below the $\gamma^{H}(\beta)$ curve and above the $\widehat{\gamma}^{L}(\beta)$ curve. Inspecting the figure, it follows that the gap between $\gamma^{H}(\beta)$ and $\widehat{\gamma}^{L}(\beta)$ grows as $\beta$ decreases, so that the range of $\gamma$ values over which the borrower is exposed to more overall risk than in the no-termination case widens as $\beta$ decreases. 
In the region above the shaded region, borrowers receive less (rather than more) high-state risk exposure than in the no-termination case, while again receiving more risk exposure in the low state. Below the shaded region, high-state risk exposure is again greater than in the no-termination case, while the change in risk exposure in the low state is ambiguous.

Conditionality, however, can be reversed, with the focus instead on $\beta$ 's effect on risk exposure conditional on $\gamma$. Viewing Figure 2 in this way, it shows that, along a horizontal line that passes through the shaded region, overall risk exposure is greater than in the notermination case when $\beta$ is sufficiently small, with the critical value (which depends on $\gamma$ ) rising toward 1 as $\gamma$ approaches zero from either direction. When $\gamma=0$, overall risk exposure is greater regardless of the value of $\beta$, a conclusion that mirrors the Corollary from above. Summarizing yields

Proposition 6. In the presence of job relocation and default, and conditional on $r_{\tau, 0}$, the borrower's overall risk exposure relative to the no-termination case depends on $\gamma$ and $\beta$ in the following fashion:

(i) Conditional on $\beta$, the range of $\gamma$ values over which the borrower is exposed to more overall interest-rate risk widens as $\beta$ decreases (as the borrower's risk aversion rises relative to that of the lender).

(ii) Conditional on $\gamma$, the range of $\beta$ values over which the borrower is exposed to more overall interest-rate risk widens (starting from a zero width) as the absolute value of $\gamma$ decreases (as the borrower's discount factor converges to that of the lender).

Note in part (ii) that, when the above-mentioned horizontal line is above or below the shaded region, no values of $\beta$ lead to more overall risk exposure, giving the $\beta$-range zero width.

\section{Implications for Mortgage Markets}

Although the preceding analysis has characterized Pareto-optimal mortgages, taking the perspective of a planner, the results carry implications for actual mortgage markets. In particular, because the lender's expected utility has been fixed at a value corresponding to the zero profit level that would be attained in a competitive market, the optimal mortgage contracts in the analysis correspond to those that would actually be generated in such a market. In

other words, a competitive market would be expected to deliver mortgage contracts that yield 
maximal borrower utility while earning a normal profit for lenders. In effect, any given borrower can be viewed as choosing his expected-utility-maximizing contract from among those that yield a normal profit.

If termination were impossible, the chosen contracts would look like those from section 2 , reflecting the extent of risk aversion of both borrowers and lenders. Highly risk-averse borrowers would choose mortgage contracts that provide them with substantial risk protection. More specifically, suppose that lenders realistically have a common value of $\sigma_{v}$, assumed positive, while borrower risk aversion is heterogeneous. Then, highly risk-averse borrowers (those with high $\sigma_{u}$ 's) will choose low- $\beta$ contracts with substantial risk protection, while borrowers with low risk aversion (low $\sigma_{u}$ 's) will choose high- $\beta$ contracts with low risk protection. Heterogeneity in borrower risk aversion will thus lead to a whole range of contracts with differing degrees of risk protection, like the range observed in the current mortgage market.

But with $\sigma_{v}$ positive, this contract range will not, strictly speaking, include FRMs, with the most risk-averse borrowers choosing mortgages where $\beta$ is small but still positive. Existing FRMs might be viewed, though, as an approximation to such low- $\beta$ contracts, overcoming the inaccuracy of this strict prediction. Note that the model's ability to generate the FRM as an optimal contract, which happens when $\sigma_{v}=0$, is no help in this regard because, with all lenders risk neutral, the theory then unrealistically implies that all mortgages will be FRMs. In other words, regardless of the extent of his risk aversion, a borrower's utility-maximizing contract will have $\beta=0$ if he faces a risk-neutral lender. Thus, lender risk aversion is crucial under the model in replicating the range of existing mortgage contracts, although it rules out in a strict sense the emergence of FRMs.

While $\gamma=0$ is required for the model to generate standard FRMs and fully adjustable ARMs, some features of actual mortgage contracts can be explained by nonzero $\gamma$ values. For example, an ARM with a teaser rate, where the initial rate has a lower markup than subsequent rates, can be generated when $\sigma_{u}=0$ and $\gamma$ is positive, with impatient consumers using the teaser to shift mortgage payments into the future. Although mortgage points do not, strictly speaking, reflect the same kind of adjustment in interest rates, they allow a similar choice, with an impatient borrower opting for a low-points mortgage in return for higher future interest 
payments.

Refinancing occurs on a regular basis in actual mortgage markets, and although it may disrupt the optimal contracts from section 2, real-world contracts are crafted to take it into account. Since refinancing tends to occur when seasoned mortgage contracts are earning profits, which then cease, its presence requires a higher initial markup over the short-term rate, relative to a world without refinancing. Refinancing may interfere with optimal risk-sharing, as seen in section 3 , but a formal solution to this problem is not available within the current analytical framework, as explained earlier. Whether the market solution (higher rates on mortgages where risk protection is high and refinancing is thus a threat) is efficient appears to be an open question.

The analysis in sections 4 and 5 also has market implications. It suggests that the possibility of job relocation or default will tend to reduce on average the extent of risk protection in the mortgages that consumers choose. Note that, even though externalities felt by lenders account for this reduced risk protection, the analysis implies that borrowers themselves will end up taking these externalities into account in their contract choices. In other words, since the lender's profit constraint incorporates the gain from the borrower's high-state job relocation and the loss from his low-state default, the externalities are built into borrower's range of contract choices and thus reflected in the mortgage he chooses.

While the previous analysis did not incorporate heterogeneity in the prospects for job relocation or default, such heterogeneity obviously exists. For example, the distribution $F(\cdot)$ of moving costs may be borrower-specific, making some borrowers more likely to relocate or default than others. If the lenders could observe these differences and segregate borrowers accordingly, then the differences would be reflected in the profit constraint and thus in the range of contracts offered to borrowers. For given $\sigma_{u}$ and $\gamma$, borrowers more prone to relocation or default would be offered and would choose contracts with less risk protection than others.

\section{Conclusion}

As explained in the introduction, much of the literature on the economics of mortgage markets has studied the FRM-ARM choice made by individual borrowers. However, to decide 
if the outcome of such a choice is efficient or approximately so, it is necessary to explore the question of optimal risk-sharing in mortgage contracts. But since only a small literature has studied this question, more research is clearly warranted. The present paper is intended to help fill this gap by developing a simplified version of Arvan and Brueckner's (1986a) model, using it to characterize optimal contracts in absence of mortgage termination, and then exploring how termination via prepayment or default affects optimal risk-sharing. The broad conclusion of the analysis is that potential mortgage termination makes higher risk exposure for borrowers optimal. The threat of refinancing, one path to prepayment, may eliminate all but the risky ARM contract from the opportunity set. Potential prepayment due to job relocation in boom times calls for a higher loan rate in such times to encourage a move, and potential default calls for a lower loan rate in bust times to encourage the borrower to stay in the house. Relative to the no-termination case, all these changes expose the borrower to more interest-rate risk.

Since the literature on optimal risk-sharing was initiated prior to the huge expansion in the secondary mortgage market, it is important to gauge the relevance of its approach, including that of the current paper, in present times when the secondary market is dominant. The issue arises because the model relates best to a world where lenders rely on deposits as the source of their mortgage funds, paying short-term rates to depositors and thus being exposed to potential interest-rate risk. But currently, the majority of mortgages are not retained by the lender, being sold in the secondary market. As a result, the lender's risk exposure arises only through the mortgages retained on his books, which constitute a minority of all loans

While the model continues to apply to these retained mortgages, which represent (despite their minority status) a substantial dollar volume given the market's huge size, a question is whether the model has any relevance for securitized mortgages. The answer is not entirely clear. To the extent that secondary-market investors rely on short-term borrowing for their funds, they are indistinguishable from lenders who rely on deposits. But for investors using their own capital for secondary-market purchases, the model appears to be less relevant. The upshot is that, while the model applies to retained mortgages, it may be less suitable as a vehicle for analyzing mortgage contracting in a world of securitization. Exploration of the contracting problem in such a world could be a task for future research. 


\section{Appendix}

This appendix shows how lender profits in the high and low states depend on the magnitude of $\gamma$, establishing parts (ii) and (iii) of Proposition 2. Assuming $\beta<1$, the lender's low-state profit $g(\gamma, \beta)-(\beta-1) \alpha+\gamma$ is positive when $\gamma=\gamma^{*}(\beta)>0$ and $g(\gamma, \beta)$ is thus zero. Since it can be shown that $\partial(g(\gamma, \beta)+\gamma) / \partial \gamma=g_{\gamma}+1$ is positive despite $g_{\gamma}<0,{ }^{7}$ it follows that there exists another critical value $\gamma^{L}<\gamma^{*}(\beta)$ such that low-state profit satisfies $g(\gamma, \beta)-(\beta-1) \alpha+\gamma<$ (>) 0 as $\gamma<(>) \gamma^{L}$. Recalling that $g(0, \beta)>0$ holds, which makes this profit expression positive when $\gamma=0$, it follows that $\gamma^{L}<0$ must hold. Finally, since $\gamma^{L}$ is implicitly defined by $g\left(\gamma^{L}, \beta\right)-(\beta-1) \alpha+\gamma^{L}=0$, it is (like $\left.\gamma^{*}\right)$ a function of $\beta$. Since $g_{\gamma}+1>0$ and $g_{\beta}-1<0$ hold, total differentiation of the last equality shows that $\gamma^{L}(\beta)$ is increasing in $\beta$.

Turning to high-state profit, since the first $v$ term in (16) has a zero argument when $\gamma=\gamma^{*}(\beta)$ while the third term's argument is positive, the argument of the second term must be negative in order for the expression to equal $(1+\theta) v(0)=\bar{\pi}$. As a result, $g(\gamma, \beta)+(\beta-1) \alpha+\gamma<$ 0 must hold, so that the lender loses money in the high state, when $\gamma=\gamma^{*}(\beta)$. Given $\partial(g+\gamma) / \partial \gamma>0$, it follows that there exists a third $\gamma$ critical value, denoted $\gamma^{H}>\gamma^{*}(\beta)>0$, such that $g(\gamma, \beta)+(\beta-1) \alpha+\gamma<(>) 0$ as $\gamma<(>) \gamma^{H}$. Finally, since $\gamma^{H}$ is implicitly defined by $g\left(\gamma^{H}, \beta\right)+(\beta-1) \alpha+\gamma^{H}=0$, it is (like $\left.\gamma^{*}\right)$ a function of $\beta$. Since $g_{\gamma}+1>0$ and since

$g_{\beta}+1>0$ can be shown to hold, ${ }^{8}$ total differentiation of the last equality shows that $\gamma^{H}(\beta)$ is decreasing in $\beta$.

When $\beta=1$, high- and low-state profits are both equal to $g(\gamma, 1)+\gamma$. Since this expression equals zero when $\gamma=\gamma^{*}(1)=0$, it follows that $\gamma^{H}(\beta)=\gamma^{L}(\beta)=\gamma^{*}(\beta)=0$ when $\beta=1$. 


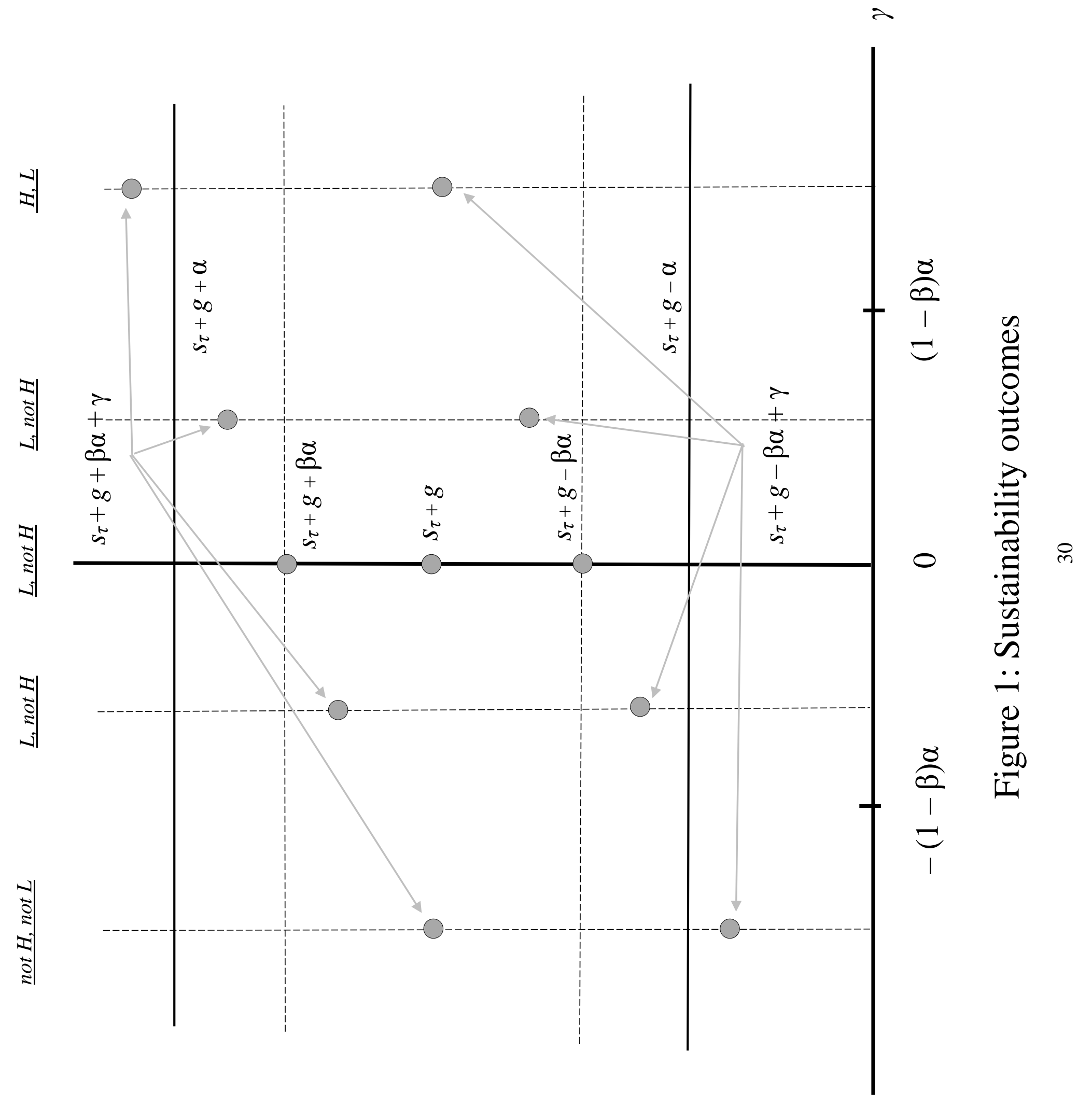




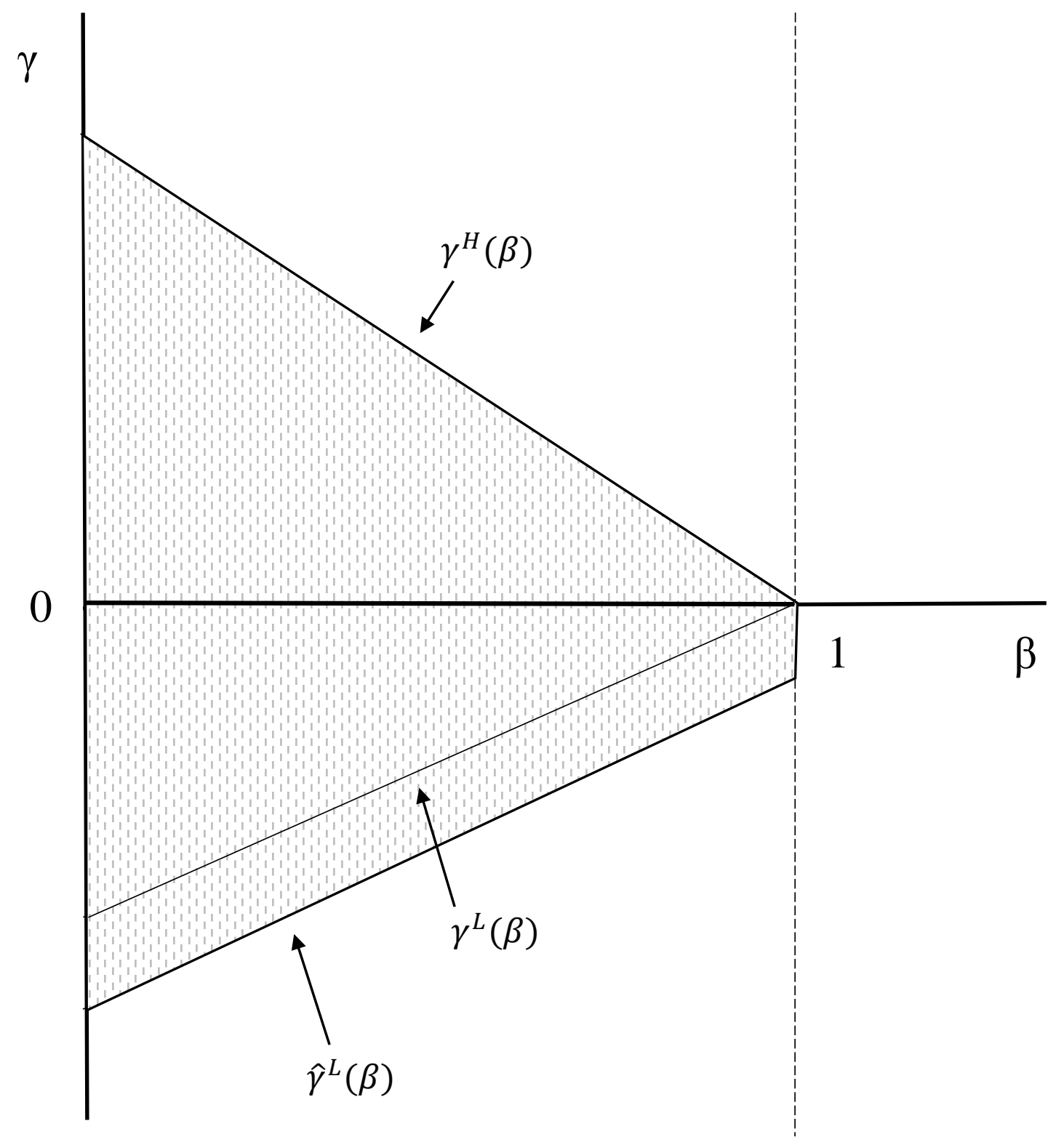

Figure 2: Parameter region with more overall borrower risk exposure 


\section{References}

Arvan, L., Brueckner, J.K., 1986. Efficient contracts in credit markets subject to interest rate risk: an application of Raviv's insurance model. American Economic Review 76, 259263.

Arvan, L., Brueckner, J.K., 1986. Risk sharing in the adjustable-rate loan market: Are existing contracts efficient? Economics Letters 22, 361-364.

BruECKNER, J.K., 1992. Borrower mobility, self-selection, and the relative prices of fixed-and adjustable-rate mortgages. Journal of Financial Intermediation 2, 401-421.

BRUECKNER, J.K., 1994. Borrower mobility, adverse selection, and mortgage points. Journal of Financial Intermediation 3, 416-441.

Brueckner, J.K., 2000. Mortgage default with asymmetric information. Journal of Real Estate Finance and Economics 20, 251275.

Brueckner, J.K., Follain, J.R., 1988. The rise and fall of the ARM: An econometric analysis of mortgage choice. Review of Economics and Statistics 70, 93-102.

Campbell, J.Y., Cocco, J.F., 2003. Household risk management and optimal mortgage choice. Quarterly Journal of Economics 118, 1449-1494.

Chan, S., 2001. Spatial lock-in: Do falling house prices constrain residential mobility? Journal of Urban Economics 49, 567-586.

Chari, V., Jagannathan, R., 1989. Adverse selection in a model of real estate lending. Journal of Finance 44, 499-508.

Demarzo, P.M., Fishman, M.J., 2007. Optimal long-term financial contracting. Review of Financial Studies 20, 2079-2128.

DeMarzo, P.M., Sannikov, Y., 2006. A continuous-time agency model of optimal contracting and capital structure. Journal of Finance 61, 2681-2724.

Dhillon, U.S., Shilling, J.D., Sirmans, C.F., 1987. Choosing between fixed and adjustable rate mortgages Journal of Money, Credit and Banking 19, 260-267.

Dokko, Y., Edelstein, R.H., 1991. Interest rate risk and optimal design of mortgage instruments. Journal of Real Estate Finance and Economics 4, 59-68. 
Dunn, K.B., Spatt, C.S., 1985. Prepayment penalties and the due-on-sale clause. Journal of Finance 40, 293308.

Edelstein, R., Urošević, B., 2003. Optimal loan interest rate contract design. Journal of Real Estate Finance and Economics 26, 127-156.

Engelhardt, G.V., 2003. Nominal loss aversion, housing equity constraints, and household mobility: Evidence from the United States. Journal of Urban Economics 53, 171-195.

Ferreira, F., Gyourko, J., Tracy, J., 2010. Housing busts and household mobility. Journal of Urban Economics 68, 34-45.

Harrison, D.M., Noordewier, T.G., Yavas, A., 2004. Do riskier borrowers borrow more? Real Estate Economics 32, 385-411.

Koijen, R.S., Hemert, O.V., Nieuwerburgh, S.V., 2009. Mortgage timing. Journal of Financial Economics 93, 292-324.

LEE, K., 2014. Fixed rate mortgages, labor markets, and efficiency. Unpublished paper, San Diego State University.

Leroy, S.F., 1996. Mortgage valuation with optimal prepayment. Review of Financial Studies $9,817-844$.

Mayer, C., Piskorski, T., Tchistyi, A., 2013. The inefficiency of refinancing: Why prepayment penalties are good for risky borrowers. Journal of Financial Economics 107, 694-714.

Nothaft, F.E., Wang, G.H., 1992. Determinants of the ARM share of national and regional lending. Journal of Real Estate Finance and Economics 5, 219-234.

Piskorski, T., TChistyi, A., 2010. Optimal mortgage design. Review of Financial Studies 23, 3098-3140.

Posey, L.L., Yavas, A., 2001. Adjustable and fixed rate mortgages as a screening mechanism for default risk. Journal of Urban Economics 49, 54-79.

SA-Aadu, J., Sirmans, C.F., 1995. Differentiated contracts, heterogeneous borrowers, and the mortgage choice decision. Journal of Money, Credit and Banking 27, 498-510.

Rosenthal, S.S., Zorn, P., 1993. Household mobility, asymmetric information, and the pricing of mortgage contract rates. Journal of Urban Economics 33, 235-253.

Stanton, R., Wallace, N., 1998. Mortgage choice: What's the point? Real Estate Eco- 
nomics 26, 173-205.

Stiglitz, J., Weiss, A., 1981. Credit rationing in markets with imperfect information. American Economic Review 71, 393-410. 


\section{Footnotes}

${ }^{1}$ Edelstein and Urošević (2003) also consider prepayment and default and derive effects on optimal risk-sharing, but because these events are exogenous and independent of the form of the mortgage contract, their findings are unrelated to the present ones. In their analysis, prepayment causes the house to be sold earlier, so that the impact of the correlation between its price and the short-term rate is moved closer to the origination date of the mortgage, affecting risk-sharing.

${ }^{2}$ When $\beta=1, \pi=v(g)+\theta v(g+\gamma)$, so that $g=0$ must hold when $\gamma=0$, implying $\gamma^{*}=0$.

${ }^{3}$ Note from (20) that an increase in $\beta$ or $\alpha$ retards refinancing in the high state, an outcome that can be understood by applying the previous reasoning. But the low-state effect is the crucial one, given that satisfaction of (19) implies refinancing in one or both states and thus unsustainability.

${ }^{4} \mathrm{~A}$ transaction cost would also be incurred for the original mortgage, but since its inclusion creates inessential notational complications, this initial cost is suppressed.

${ }^{5}$ Note that the refinancing issue does not arise in standard models of mortgage contracts in the literature, as the models do not consider multiple generations of borrowers. However, if the literature were to make the more realistic assumption that multiple generations exist at a given point in time, it would face the same issue.

${ }^{6}$ The possibility of prepaying the mortgage in order to pay rent rather than mortgage interest (which could represent a higher outlay) can be ruled out if the transactions cost $c$ is sufficiently large.

${ }^{7}$ From the previous analysis, $g_{\gamma}+1=-\pi_{\gamma} / \pi_{g}+1=-\pi_{\gamma} /\left(v^{\prime}(g)+\pi_{\gamma}\right)+1>0$.

${ }^{8}$ From the previous analysis,

$$
g_{\beta}+\alpha=\left(1-\frac{\theta p v^{\prime H}-(1-p) v^{\prime L}}{v^{\prime}(g)+\theta\left(p v^{\prime H}+(1-p) v^{\prime L}\right)}\right) \alpha>0 .
$$

